\title{
Resettling refugee physicians into their profession of choice
}

\author{
Jacek Orzylowski
}

\begin{abstract}
The incoming population of refugees is putting more strain on an already taxed medical system here in Canada. To boot, this new population is at greater risk of a wider range of illness and profound trauma rarely encountered at such a scale by Canadian general practitioners-the primary point of contact for refugees entering the Canadian health care system. Additionally, countless refugees become underemployed after settling into their new country-this includes many medical professionals. By recruiting these medically trained refugees into general practice, they can be assigned specifically to their population cohort, bridging the gaps of location-specific illness, trauma, language, and culture, all of which will enhance the patient-physician relationship and subsequent care. However, it is imperative to make sure these international physicians are competent and mentally fit to work after their potential ordeals. A balance might be struck between easing licentiate exam requirements, subsidizing their training in their vulnerable transition period, or similar modifications at the variable provincial levels of regulatory medicine.
\end{abstract}

\section{A CRISIS AT HOME AND ABROAD}

The dispersion of refugees worldwide is putting significant strain on health care systems-this is especially true in Canada, which has taken in a disproportionate number of families. ${ }^{1}$ In addition, this population is burdened with many medical complexities: subpar screening, a wider array of infectious diseases, and a bottomless well of damage done through the trauma of war and/or poverty, ${ }^{2,3}$ all exacerbated by the gulfs between cultures, customs, and languages. However, embedded within the population in question are individuals possibly more capable of navigating this medical maze than Canadian doctors-health care providers seeking refuge in Canada alongside their countrymen. Funding these individuals through their transition into the Canadian medical system would offer them a chance to recoup some of the life they were forced to flee, while also providing benefits to Canada at large.

Refugees are thrust, often without preparation, into an environment where language and culture can conflict with their own. ${ }^{4}$ The consideration of language is of paramount importance in obtaining an accurate medical history for treatment or referral, while culture, perhaps more subtle, is nevertheless integral to creating rapport for more efficacious treatment. Since the health care provider in the proposed scenario would come from the same country, or more specifically, the refugee population, language ceases to be an issue, whilst a shared culture expedites the relationship with the patient, therefore avoiding social mistakes. ${ }^{5}$

\section{REFUGEE PHYSICIANS COMPARED TO CANADIAN PHYSICIANS}

Although one may look at the above points and argue instead to employ a diverse staff of professionals from within Canada-that speak the relevant languages and were brought up in the culturethis denies the documented dearth of (rural) family physicians in general, ${ }^{6,7}$ let alone those with such worldly credentials. It is important to highlight the role of general practitioners in this situation, as they will be the primary point of contact for resettling refugees. Canada is not lacking in hospitalists to manage the specific issues which arise in at-risk populations; however, family physicians-the gatekeepers to these specialists-are already understaffed. ${ }^{7}$ Furthermore, a more precise work-up is needed to refer ill individuals to the correct specialists because this population is at greater risk for a wider range of disease.,3

It is important to touch on another major obstacle in refugee health care-trauma. ${ }^{4}$ Having physicians who had experienced this trauma first-hand could greatly accelerate rapport, as shared trauma has been shown to increase bonding. ${ }^{8}$ However, there remains the risk that the trauma could affect the refugee physician to the point of making them unfit to practice. Such a distinction would ideally be made upon their arrival and medical work-up in Canada, at which point adequate therapy would be offered if those individuals decided to pursue a career in medicine again.

While offering viable transitions to health care providers from within refugee populations offers many benefits to the Canadian medical system, several caveats remain. One was mentioned previously-it is imperative to give refugee physicians an in-depth psychological work-up to ensure that they are fit enough to practice. If not, they should be offered the care they need to heal in the face of the trauma they experienced.

\section{SPECIFICS OF REFUGEE DOCTOR PLACEMENT}

If ready to work, the proposed paradigm would expect these refugee physicians to take on the role of a family doctor, irrespective of their specialties abroad. This may come across as an unfair stipulation to place upon highly-qualified professionals, but would be an improvement over the current state of affairs. The government funded a focused study on the backgrounds of 22,000 Canadian cab drivers, and found that approximately half were immigrants, almost five percent of whom were trained as physicians. ${ }^{9}$ While minimal data exists regarding other careers apart from transport, one 
might expect similar demographics among other similar careers; it is likely that such underemployed physicians would prefer to step laterally from their specialties into general practice to at least return to the health care field. Furthermore, this would alleviate the missed economic potential of such individuals for the country under the current system. Shifting the training of such a specialist towards family medicine would be done under the supervision of a GP during the required twelve months of training to receive the Licentiate of the Medical Council of Canada (LMCC)-this avenue of transition to medical work in Canada will be explored in more detail below.

Those worried about the quality of patient care might wonder at the standards of medical education in the countries of origin of these refugees. A study published in the British Medical Journal highlighted the better survival rates of patients treated by internationally educated doctors than American physicians. ${ }^{10}$ This was in stark contrast to public perception. However, the countries studied included only India, Pakistan, Ireland, and the Philippinesthere is much less data available for the countries of refugee origin.

\section{A DIFFERENT BUREAUCRATIC AND CULTURAL LANDSCAPE}

Additionally, the detailed workings of Canada's medical infrastructure are unlikely to perfectly mirror the relevant bureaucracies in other countries, especially as each Canadian province has its own methodology. Ideally family physicians, the gatekeepers of said system, would be well-versed in how the bureaucratic landscape works in order to maximally benefit their patients and minimize hassle. It is highly unlikely that refugees would be familiar enough with this landscape to navigate it successfully; that said, they would be highly motivated to learn well and to learn quickly.

Finally, it behooves the medical system to interrogate the refugees' country of origin's values as relating to women's and mental health. Even in the Global North, these facets of medicine have only recently been explored, and further validation is still ongoing. ${ }^{11,12}$ It would be integral, especially for general practitioners, that they do not hold opinions in these domains that have been superseded by the science of best practice; if this were to be the case, hopefully the refugee physician would be corrected in their practise of outdated medicine.

\section{PRACTICAL AVENUES TO ELICIT CHANGE}

It is up to the relevant authorities to weigh these caveats against the benefits for the incoming refugee populations. If these authorities decide the refugee crisis merits such a recruitment of refugee general practitioners, there are several mechanisms which might make the integration of these physicians more viable. Some of the most important hurdles for international physicians in Canada are the exams to obtain their LMCC. Within this regulatory paradigm, one might modify the qualifying examination, either part of the licensing exam proper, or even the prerequisite twelve months of postgraduate clinical medical training. However, the LMCC is not a license to practise medicine-such a privilege is up to the discretion of provincial medical regulatory bodies; ${ }^{13,14}$ indeed, delving too far into bureaucratic details is beyond the scope of this investigation. Each individual regulatory body would ideally interrogate its pathways to practice. However, if it was made clear to refugee physicians that their twelve months of pre-requisite training would be funded by the government, then there would be less pressure for these people to take on whatever job is readily available, such as driving a cab. Since this training is done under the supervision of a licensed doctor, this period would be ideal for these highly-motivated refugees to acclimatize to Canada. Whatever cost this paid training incurs would likely be evened by the reduced instances of culture shock, miscommunications, and loss of followups (and subsequent drop in quality health care) that might be expected when treating newly resettled refugees.

\section{CONCLUSION}

Generally, if refugee health care providers were made aware that they could receive subsidized training, for example, to return them to their chosen profession, dependent on specialist availabilities, then many of them could work among familiar faces while they acclimatized to the new culture. Meanwhile, they would be addressing the dearth of general practitioners in Canada who are already overworked. With the right implementation, provincial and federal governments could forge this emergency into a solution that could benefit current and future Canadians for decades to come.

\section{REFERENCES}

1. Markusoff J. Canada now brings in more refugees than the U.S. MacLean's [Internet]. 2019 Jan 23 [cited 2018 Dec 16];News:[about 2 p.]. Available from: https://www.macleans.ca/news/canada/refugeeresettlement-canada/

2. Pottie K, Greenaway C, Feightner J, et al. Evidence-based clinical guidelines for immigrants and refugees. CMAJ. 2011;183(12):824-925. https://doi.org/10.1503/cmaj.090313

3. Hwang J. Public health response and health status of asylum seekers: A review of the international literature and implications for the Canadian context [Internet]. NCCID. 2017 [cited 2018 Dec 16]; 352. Available from: https://nccid.ca/publications/public-health-responsehealth-status-asylum-seekersreview-international-literatureimplications-canadian-context/

4. Robertshaw L, Dhesi S, Jones L. Challenges and facilitators for health professionals providing primary healthcare for refugees and asylum seekers in high-income countries: a systematic review and thematic synthesis of qualitative research. BMJ Open. 2017;7(8):e015981. https://doi.org/10.1136/bmjopen-2017-015981.

5. Crawford T, Candlin S, Roger P. New perspectives on understanding cultural diversity in nurse-patient communication. Collegian. 2017;24(1):63-9. https://doi.org/10.1016/j.colegn.2015.09.00.

6. Physician data centre: Canadian physician statistics [Internet]. Canadian Medical Association. 2018 [cited 2018 Dec 16]. Available from: https://www.cma.ca/En/Pages/canadianphysician-statistics. $\underline{\operatorname{aspx}}$

7. Brend Y. We're graduating more doctors than ever, so why is it so hard to find a GP? CBC News [Internet]. 2017 May 4 [cited 2018 Dec 16];Analysis:[about 5 p.]. Available from: https://www.cbc.ca/news/ canada/british-columbia/bc-doctor-shortage-medical-fees-1.4100251

8. Bastian B, Jetten J, Ferris L. Pain as social glue. Psychol Sci. 2014;25(11):2079-85. https://doi.org/10.1177/0956797614545886.

9. Xu L. Who drives a taxi in Canada? [Internet] Citizenship and Immigration Canada; 2012 [cited 2018 Dec 16]. Available from: https:// 
www.canada.ca/content/dam/ircc/migration/ircc/english/pdf/ research-stats/taxi.pdf

10. Tsugawa Y, Jena A, Orav E, et al. Quality of care delivered by general internists in US hospitals who graduated from foreign versus US medical schools: observational study. BMJ. 2017;356:j273. https://doi. org $/ 10.1136 /$ bmj.j273

11. Hoffmann D, Tarzian A. The girl who cried pain: a bias against women in the treatment of pain. J Law Med Ethics. 2003:29:13-27. https://doi. org $/ 10.2139 /$ ssrn. 383803

12. Temmerman M, Khosla R, Laski L, et al. Women's health priorities and interventions. BMJ. 2015;351:h4147. https://doi.org/10.1136/bmj.h4147

13. Licentiate of the Medical Council of Canada. Medical Council of Canada [Internet]. 2018 [cited 2018 Dec 16]. Available from: https:// mcc.ca/about/lmcc/

14. Health workforce planning branch: international medical graduates, Ontario Ministry of Health and Long-Term Care [Internet]. 2018 [cited 2018 Dec 16]. Available from: http://www.health.gov.on.ca/en/pro/ programs/hhrsd/physicians/international_medical_graduates.aspx 